\title{
Detection of intestinal and extra-intestinal strains of enterotoxigenic Bacteroides fragilis by the HT-29 cytotoxicity assay
}

\author{
ANNALISA PANTOSTI, MARINA CERQUETTI, R. COLANGELI and F. D'AMBROSIO \\ Laboratory of Bacteriology and Medical Mycology, Istituto Superiore di Sanità, Viale Regina Elena 299. \\ 00161 Rome, Italy
}

\begin{abstract}
Summary. Bacteroides fragilis strains with enterotoxic activity can be isolated from the faeces of newborn farm animals with diarrhoea and are called enterotoxigenic B. fragilis (ETBF). These strains can now be detected in an in-vitro cytotoxicity assay with HT-29 cells. In this study, 146 B. fragilis strains (95 faecal and 40 extra-intestinal isolates) and 64 Bacteroides isolates belonging to species other than $B$. fragilis were tested for their ability to produce enterotoxin. Sixteen strains of ETBF were identified; all belonged to the fragilis species and represented $11 \%$ of all B. fragilis examined. The prevalence was similar among extraintestinal and faecal strains, $11.5 \%$ and $10 \%$, respectively. The production of enterotoxin in clinical isolates appeared to be associated with infections where tissue destruction was more prominent. Enterotoxigenicity was not associated with the presence of a plasmid and the plasmid profiles of ETBF strains that harboured plasmids were different. These results show that enterotoxin production by human isolates of $B$. fragilis is not uncommon and could represent a new virulence factor of $B$. fragilis.
\end{abstract}

\section{Introduction}

The role of anaerobic non-spore-forming bacteria in the ecology of the normal intestinal flora is considered to be mainly beneficial. Their metabolic activities are important for the health of the individual ${ }^{1}$ and are thought to be responsible for resistance to colonisation by enteric pathogens. ${ }^{2}$ However, some of these bacteria, notably those belonging to the genus Bacteroides, can cause severe infections at extra-intestinal sites. ${ }^{3}$ $B$. fragilis is the species most frequently isolated from infections in man, ${ }^{4}$ but it was not implicated as a cause of intestinal diseases until the last 10 years.

In 1984, Myers et al. isolated enterotoxigenic strains of $B$. fragilis (ETBF) from the faeces of neonatal lambs with diarrhoea. ${ }^{5}$ The enterotoxigenicity of these strains was demonstrated experimentally by their ability to elicit fluid accumulation in the lamb ligated intestinal loop test. Similar strains were isolated from the faeces of diarrhoeic calves, ${ }^{6}$ piglets $^{7}$ and foals. ${ }^{8}$ Studies in man showed that individuals with or without diarrhoea can harbour ETBF strains in the intestine, ${ }^{9}$ but few data are available concerning the distribution of ETBF strains and their pathogenic potential in man.
The study of ETBF was stimulated by the demonstration that culture supernates of ETBF strains induce morphological alterations in a cultured cell-line from a human colon carcinoma, HT-29. ${ }^{10}$ Van Tassel et al. purified a protein of $c .20 \mathrm{kDa}$ which was responsible for both enterotoxic and cytotoxic activities $^{11}$ and it became possible to use this in-vitro cytotoxicity test to detect ETBF instead of the cumbersome in-vivo procedure of the ligated intestinal loop. Moreover, as $B$. fragilis is primarily an extraintestinal pathogen, the cytotoxic potential of the toxin suggested that it could participate in the invasive and destructive processes of extra-intestinal $B$. fragilis infections.

The aim of this study was to test $B$. fragilis isolates from faecal and extra-intestinal samples for their ability to produce cytotoxic changes in HT-29 cells.

\section{Materials and methods}

\section{Bacterial strains}

The bacterial strains used in this study comprised 146 B. fragilis strains and 64 strains of other Bacteroides spp. Of the B. fragilis strains, 95 were from clinical (i.e., extra-intestinal) samples and included the reference strains NCTC nos. 9343, 2429, 11295 and 
11870 and ATCC 23745; 51 were from faecal samples of adults and children, with or without diarrhoea, and were isolated in different geographical areas of Italy. For Bacteroides spp. other than fragilis, 24 extraintestinal and 40 faecal isolates were examined, comprising B.vulgatus (28 strains), B. thetaiotaomicron (15), B. distasonis (9), B. uniformis (5), B. ovatus (3), B. merdae (3) and $B$. caccae (1). The enterotoxigenic $B$. fragilis strain ATCC 43858 was used as a positive control. Bacteroides strains were identified by conventional methods ${ }^{12}$ and, when necessary, identity was confirmed by a commercially available enzyme method, rapid ID32 A (bioMérieux sa, Marcy-l'Etoile, France).

\section{Enterotoxin production}

To assess enterotoxin production, each Bacteroides strain was grown overnight in Brain Heart Infusion (BHI) Broth (Oxoid, Basingstoke) supplemented with yeast extract (Oxoid) $0.5 \%$ and haemin $0.005 \%$ in an anaerobic cabinet (Microflow Anaerobic System, $\mathrm{MDH}$ Ltd, Andover, Hampshire) at $37^{\circ} \mathrm{C}$. The cultures were centrifuged at $8000 \mathrm{~g}$ in an Eppendorf microfuge and the supernates were frozen immediately and kept at $-20^{\circ} \mathrm{C}$ until used.

\section{Cytotoxicity assay}

HT-29 cells were grown in 50-ml flasks in RPMI 1640 medium with glutamine (Gibco, Life Technologies Ltd, Paisley) supplemented with penicillin $100 \mathrm{IU} / \mathrm{ml}$, streptomycin $100 \mu \mathrm{g} / \mathrm{ml}$ and heatinactivated fetal bovine serum (Hyclone Laboratories Inc., Logan, UT, USA) $15 \%$, hereafter referred to as medium, at $37^{\circ} \mathrm{C}$ in air with $\mathrm{CO}_{2} 5 \%$. Cells were transferred to fresh medium with a 1 in 2 dilution three times a week. For the cytotoxicity assay, HT-29 cells from one flask were resuspended in $20 \mathrm{ml}$ of medium, distributed $(200 \mu \mathrm{l} /$ well) into a $96-$ well microtitration plate (Falcon, Becton Dickinson, Lincoln Park, NJ, USA) and allowed to grow for 2-3 days until discrete clusters of cells were visible (fig. 1, panel A). Before the assay the medium was removed and $180 \mu \mathrm{l}$ of fresh medium without serum was added to each well; $20 \mu \mathrm{l}$ of two-fold dilutions of bacterial culture supernates were then inoculated into the wells in duplicate. The plate was incubated at $37^{\circ} \mathrm{C}$ in air with $\mathrm{CO}_{2} 5 \%$ and then examined after 2 and $4 \mathrm{~h}$ for the presence of the typical toxin-induced cytopathic changes. The culture supernates were considered to contain $B$. fragilis enterotoxin if a cytopathic effect was visible that was neutralised by specific antiserum (see below). The cytotoxic titre was the highest dilution of the culture supernate that affected at least $50 \%$ of the cells after incubation for $4 \mathrm{~h}$.

\section{Production of antiserum to B. fragilis enterotoxin}

A polyclonal antiserum against $B$. fragilis enterotoxin was produced in a New Zealand White rabbit immunised with a crude enterotoxin antigen prepared by the methods of Van Tassel et al. ${ }^{11}$ Briefly, the highly toxigenic strain NCTC 11295 was grown overnight in $1 \mathrm{~L}$ of BHI broth. Ammonium sulphate was added to the culture supernate to $70 \%$ saturation and left overnight with continuous stirring. The precipitate was harvested by centrifugation $(10000 g)$, resuspended in $25 \mathrm{ml}$ of $50 \mathrm{~mm}$ Tris $\mathrm{HCl}, \mathrm{pH} 7.5$, containing the protease inhibitor TPCK (Sigma) $1 \mathrm{mg} / \mathrm{ml}$, dialysed extensively against the same buffer and concentrated to a final volume of $10 \mathrm{ml}$ by an Amicon ultrafiltration apparatus equipped with a YM 10 membrane (Amicon Division, W. R. Grace and Co., Danvers, MA, USA). Samples were applied to a PD-10 column (Pharmacia LKB Biotechnology, Uppsala, Sweden) and eluted with Tris- $\mathrm{HCl}$ buffer to complete desalting. This preparation was emulsified with an equal volume of Freund's complete adjuvant and $1 \mathrm{ml}$ was injected subcutaneously in four different sites of the back of a New Zealand White rabbit. Three more doses of $0.5 \mathrm{ml}$ of antigen preparation with an equal volume of Freund's incomplete adjuvant were injected intramuscularly at 2-week intervals. The rabbit was bled 10 days after the last injection.

\section{Neutralisation test}

The culture supernate from each strain was diluted to a concentration four-fold higher than the cytotoxic titre and then mixed with the same volume of doubling dilutions of anti-enterotoxin rabbit serum or normal rabbit serum. After incubation at $37^{\circ} \mathrm{C}$ for $30 \mathrm{~min}$, $20 \mu \mathrm{l}$ of each mixture was inoculated into HT-29 cells in microtitration wells containing $180 \mu \mathrm{l}$ of medium. Neutralisation was indicated by the lack of any cytotoxic effect.

\section{Plasmid fingerprinting}

To assess the possible correlation between enterotoxin production and the presence of plasmids, extrachromosomal DNA was extracted from the ETBF strains, including the reference strain ATCC 43858 , by a modification of the method of Birnboim and Doly. ${ }^{13}$ Strains were grown overnight in $10 \mathrm{ml}$ of pre-reduced $\mathrm{BM}$ broth $^{14}$ at $37^{\circ} \mathrm{C}$ in the anaerobic cabinet. Cells were pelleted by centrifugation $(4000 \mathrm{~g})$ and washed once in TES buffer $(50 \mathrm{~mm}$ Tris- $\mathrm{HCl}, 5 \mathrm{~mm}$ EDTA, $50 \mathrm{~mm} \mathrm{NaCl}$ ). The pellets were then resuspended in $100 \mu \mathrm{l}$ of $50 \mathrm{~mm}$ glucose with lysozyme $2 \mathrm{mg} / \mathrm{ml}$ in a buffer containing $25 \mathrm{~mm}$ Tris- $\mathrm{HCl}, 10 \mathrm{~mm}$ EDTA, $\mathrm{pH} 8.0$, and kept at $37^{\circ} \mathrm{C}$ for $10 \mathrm{~min} ; 200 \mu \mathrm{l}$ of $0.2 \mathrm{~N}$ $\mathrm{NaOH}$ with SDS $1 \%$ and then $150 \mu \mathrm{l}$ of $3 \mathrm{M}$ potassium acetate $(\mathrm{pH} 4.8)$ were added. After centrifugation $(10000 \mathrm{~g})$ in an Eppendorf centrifuge, the supernates were treated twice with equal volumes of phenol:chloroform $(1: 1)$. The aqueous phases were precipitated with 2 volumes of absolute ethanol and kept at $-80^{\circ} \mathrm{C}$ for $30 \mathrm{~min}$. The pellets obtained by centrifugation $(10000 \mathrm{~g})$ were dried and resuspended 

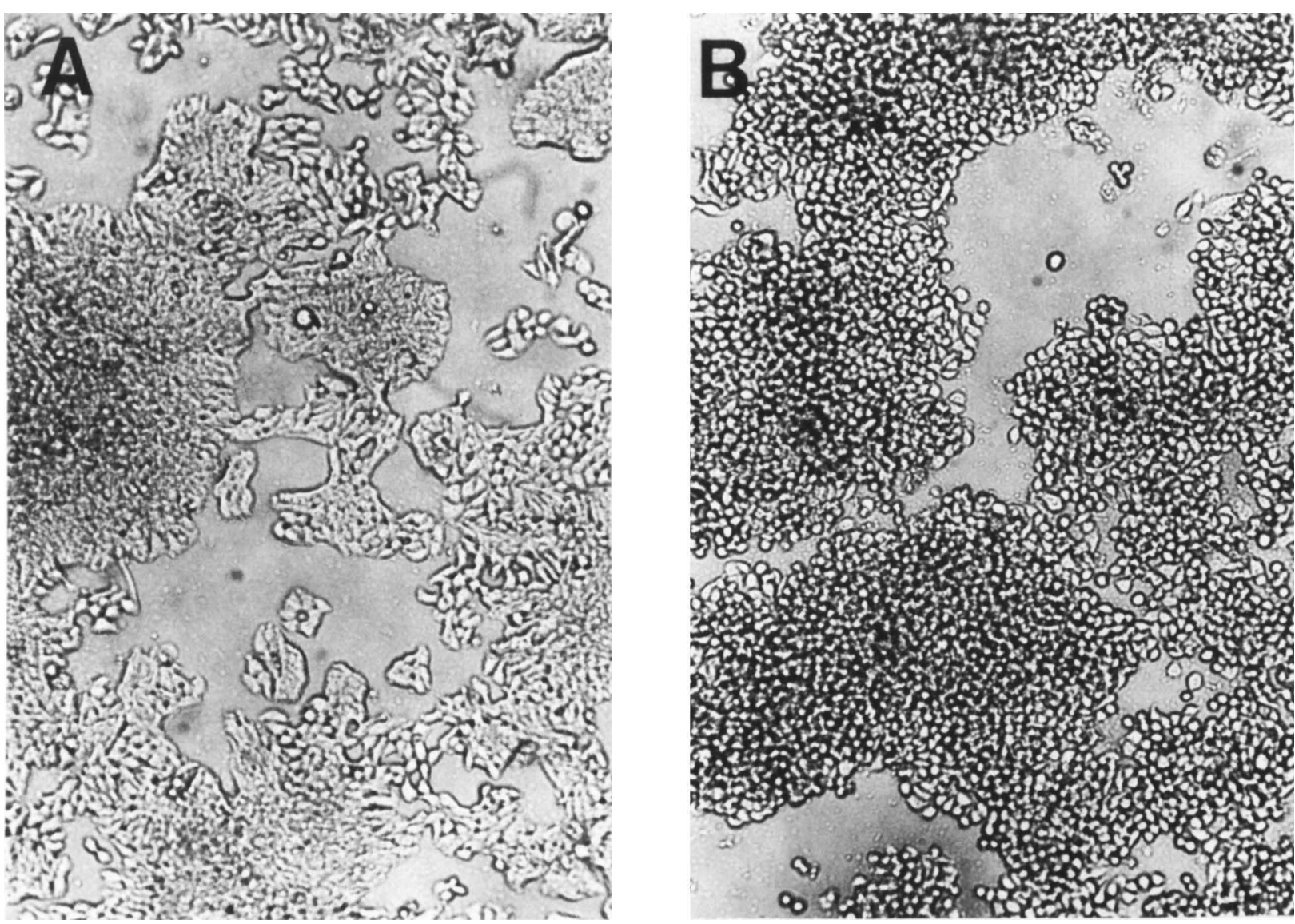

Fig. 1. Effect of broth culture supernates of $B$. fragilis on HT-29 cells after exposure for $4 \mathrm{~h}$ (magnification $100 \times$ ). Panel A, nonenterotoxigenic B. fragilis; B, ETBF reference strain ATCC 43858.

in $50 \mu$ of TE buffer (10 mM Tris- $\mathrm{HCl}, 1 \mathrm{~mm}$ EDTA, $\mathrm{pH} 8 \cdot 0$ ) containing RNAase (Boehringer Mannheim GmbH Biochemica, Mannheim, Germany) $20 \mu \mathrm{g} / \mathrm{ml}$ and left at room temperature for $30 \mathrm{~min}$. Each sample $(10 \mu \mathrm{l})$ was loaded on to an agarose $0.7 \%$ gel, run at $60 \mathrm{~V}$ for $2 \mathrm{~h}$ and viewed under UV light. HindIIIcleaved $\lambda$ DNA (New England Biolabs, Beverly, MA, USA) was used as mol.-wt marker.

\section{Results}

\section{Cytotoxicity test and detection of ETBF}

HT-29 cells grown by this method appear as discrete clusters or "islets" of cells inside which the borders of the single cells are ill-defined (fig. 1, panel A). The

Table I. Enterotoxin production by Bacteroides strains from different sources

\begin{tabular}{ll|ccc}
\hline \multirow{2}{*}{ Species } & Source & \multicolumn{3}{|c}{ Number of strains } \\
\cline { 3 - 5 } & & tested & toxin + ve & $\%$ \\
\hline \multirow{2}{*}{ B. fragilis } & Clinical & 95 & 11 & $11 \cdot 5$ \\
& Faeces & 51 & 5 & 10 \\
Other Bacteroides spp. & Clinical & 24 & 0 & 0 \\
& Faeces & 40 & 0 & 0 \\
\hline
\end{tabular}

cytotoxic effect shown by cells exposed to the supernate of the reference enterotoxic strain ATCC 43858 was clearly visible after $2 \mathrm{~h}$ and reached a maximum at $4-5 \mathrm{~h}$. The affected cells appeared rounded and more refringent, with clear outlines, and they tended to detach one from the other (fig. 1, panel B). The rounding effect was more prominent at the edges of the cell clusters. The supernates of $B$. fragilis strains considered to be ETBF induced identical cytotoxic changes.

Table I summarises the production of enterotoxin by the Bacteroides strains examined; 16 ETBF strains were found. The percentages of ETBF strains among clinical and faecal isolates were approximately the same ( 11.5 and $10 \%$, respectively). In all cases, the cytotoxic effect was neutralised by the immune rabbit anti-enterotoxin antiserum to a dilution of 1 in 8 . The non-immune rabbit serum neutralised the cytotoxic effect only when used undiluted. None of the other Bacteroides spp. produced cytotoxic changes in HT-29 cells.

Table II shows the cytotoxic titres of the ETBF strains; the range was $20-320$, with a modal value of 80. Strains from extra-intestinal infections tended to have higher cytotoxic titres than strains from faeces. The source of isolation was known for six of the 11 ETBF strains from extra-intestinal infections: they were from relatively uncommon $B$. fragilis-associated 
Table II. Source and cytotoxic titre of 16 ETBF strains and reference strain ATCC 43858

\begin{tabular}{ll|c}
\hline \multicolumn{1}{c|}{ Source } & Cytotoxic titre \\
\hline Strain no. & & 20 \\
PR254 & Abdominal abscess & 40 \\
13141 & NR & 80 \\
B5 & Osteomyelitis & 80 \\
B32 & NR & 80 \\
CM3 & Ascites & 80 \\
CM14 & Biliary fistula & 160 \\
NCTC11295 & Enteric fistula* & 160 \\
B52 & NR & 160 \\
B45 & Infection of hip prothesis & 160 \\
B34 & NR & 320 \\
B69 & NR & 80 \\
PG148 & Faeces $\dagger$ & 40 \\
AN209 & Faeces $\dagger$ & 80 \\
PA5 & Faeces $\ddagger$ & 80 \\
ANT1 & Faeces $\ddagger$ & 80 \\
ANT2 & Faeces $\ddagger$ & 40 \\
ATCC43858 & Reference strain (faeces) & \\
\hline
\end{tabular}

NR, not reported.

* From Ingham et al. ${ }^{18}$

$\dagger$ Children with diarrhoea.

$\ddagger$ Healthy adults.

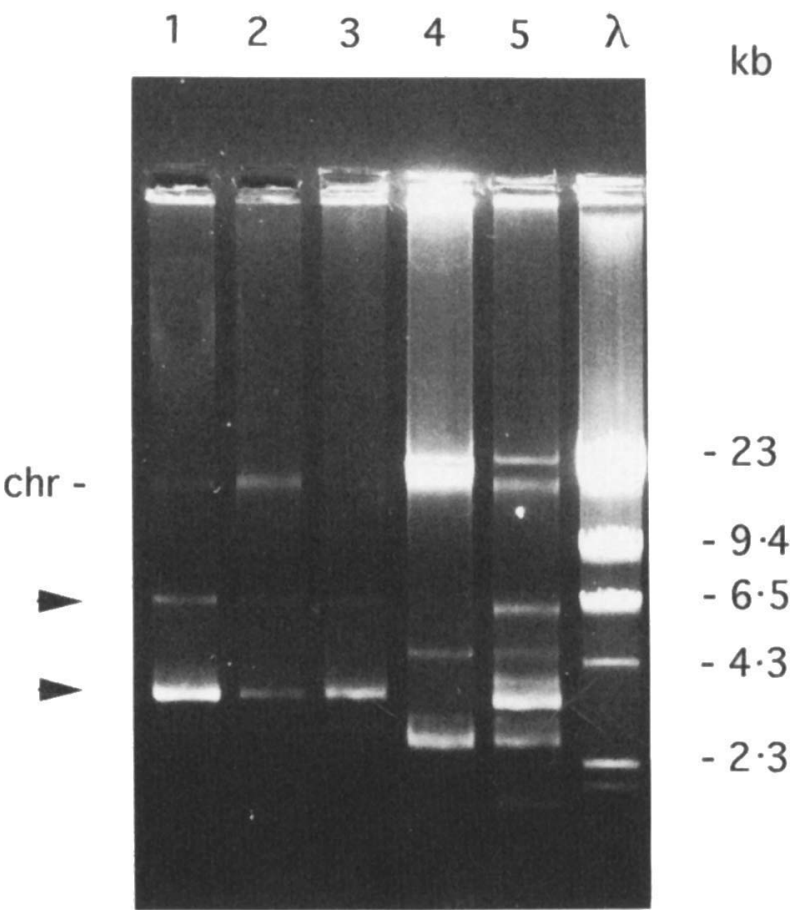

Fig. 2. Agarose gel electrophoresis of plasmid DNA preparations from ETBF strains. Lane 1, ATCC 43858; 2, B45; 3, B32; 4, B5; 5, B34; $\lambda$, HindIII-digested $\lambda$ DNA; chr, chromosomal DNA. The $3 \cdot 5$ - and $6 \cdot 5-\mathrm{kb}$ bands are indicated.

infections, such as bone infections and fistulas. Of the five ETBF strains from faeces, two were from 1-yearold children with diarrhoea and three from healthy adults. Specifically, two strains (ANT1 and ANT2) were isolated from the same stool sample of a student actively engaged in ETBF research in the laboratory. The two strains were isolated from different selective plates (data not shown) and were found to be different by plasmid fingerprinting (see below). The student was symptom-free and carried at least one of the two toxigenic strains after 1 month.

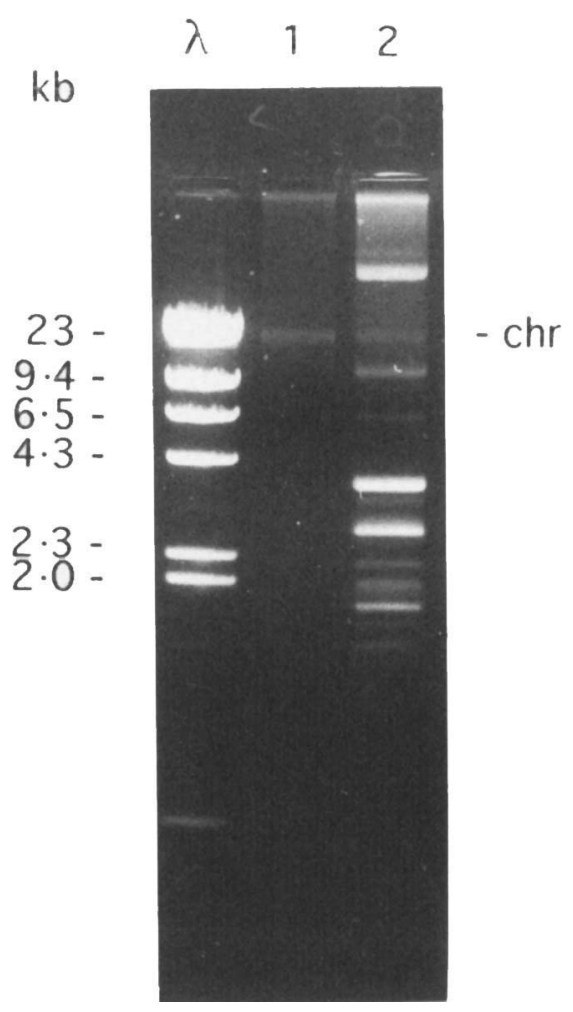

Fig. 3. Agarose gel electrophoresis of plasmid DNA preparations from two ETBF isolates from the same subject: $\lambda$, chr, as in fig. 2 .

\section{Plasmid fingerprinting}

Of the $16 \mathrm{ETBF}$ strains, eight harboured plasmids, as did the reference strain ATCC 43858. However, the plasmid patterns were different: one, two or more plasmids were present, of both high and low mol. wt (fig. 2). Most frequently, two extra-chromosomal DNA bands were visible, of $c .6 .5$ and $3.5 \mathrm{~kb}$. When two strains from the same subject were examined for their plasmid contents, they were different (fig. 3); only one of the two contained several extra-chromosomal DNA bands.

\section{Discussion}

The description 10 years ago of an enterotoxin produced by $B$. fragilis suggested new hypotheses about the role of this micro-organism in various infections. As the first recognition of this toxin was in strains isolated from the faeces of diarrhoeic farm animals, its involvement in the aetiology of diarrhoea was assumed. Studies in human subjects demonstrated the presence of ETBF, ${ }^{8,15}$ but did not corroborate a role for these strains in diarrhoeal diseases. Apart from sporadic isolations, two large prospective controlled studies were performed, one in a defined Apache population, ${ }^{16}$ and the second in a large number of children. ${ }^{17}$ The only significant association of ETBF with diarrhoea was limited to a subpopulation in the first study (children aged 13-36 months).

The weak association of ETBF with diarrhoea does 
not exclude the hypothesis that ETBF strains, being producers of an enterotoxin that also has cytotoxic activity, could be at an advantage in causing extraintestinal infections. As an initial investigation of this hypothesis, the frequency with which ETBF strains are isolated from extra-intestinal versus intestinal samples needed to be assessed and the present study aimed to identify ETBF strains among $B$. fragilis isolates from both intestinal and extra-intestinal samples. The HT29 cytotoxicity assay was easy to perform and reproducible; the cytotoxic effect was clearly recognisable with minimal experience and showed a clearcut endpoint. By this assay, with a reference enterotoxigenic strain as control and an anti-enterotoxin rabbit serum to neutralise the cytotoxic effect, several ETBF strains were identified. This is the first report of ETBF strains outside the USA; most of the strains examined were isolated in Italy, although the reference strain NCTC 11295, which proved to be toxigenic, was a metronidazole-resistant strain isolated in the UK..$^{18}$ Therefore, ETBF strains are probably distributed world-wide.

Enterotoxin production was found only in the species B. fragilis; no strains of the related Bacteroides spp. produced changes of any kind in HT-29 cells. Moreover, approximately the same ratio of ETBF to total strains was found for strains from both faecal and extra-intestinal sources. This observation might imply that enterotoxin production is a "neutral" characteristic that does not provide any selective advantage over non-enterotoxic strains. However, a closer examination of the sources of ETBF demonstrates that an appreciable proportion of high-titre toxin-producing strains were isolated from uncommon pathological conditions, e.g., osteomyelitis and fistulas, where destructive processes are prominent. In terms of the pathogenesis of B. fragilis-induced infection, it is well established that the polysaccharide capsule of this species is essential in abscess formation through the presence of oppositely charged groups on

\section{References}

1. Drasar BS, Hill MJ (eds). Human intestinal flora. London, Academic Press. 1974.

2. Freter R. Experimental enteric shigella and vibrio infections in mice and guinea pigs. $J$ Exp Med 1956; 104: 411-418.

3. Gorbach SL, Bartlett JG. Anaerobic infections. $N$ Engl J Med 1974: 290 : 1177-1184.

4. Willis AT. Abdominal sepsis. In: Duerden BI, Drasar BS (eds) Anaerobes in human disease. London, Edward Arnold. 1991: 197-223.

5. Myers LL, Firehammer BD, Shoop DS, Border MM. Bacteroides fragilis: a possible cause of acute diarrheal disease in newborn lambs. Infect Immun 1984; 44: 241-244.

6. Myers LL, Shoop DS, Firehammer BD, Border MM. Association of enterotoxigenic Bacteroides fragilis with diarrheal disease in calves. $J$ Infect Dis 1985; 152: $1344-1347$.

7. Myers LL, Shoop DS. Association of enterotoxigenic Bacteroides fragilis with diarrheal disease in young pigs. Am J Vet Res 1987; 48: 774-775.

8. Myers LL, Shoop DS, Byars TD. Diarrhea associated with enterotoxigenic Bacteroides fragilis in foals. Am J Vet Res $1987 ; 48$ : $1565-1567$. the bacterial surface. ${ }^{19,20}$ It could be speculated that the enterotoxin might play a role in those invasive B. fragilis infections where an abscess is not the sole or principal manifestation. However, further studies of this hypothesis are needed.

ETBF strains were found among unselected faecal isolates, from children with diarrhoea and adults without intestinal symptoms. The existence of healthy carriers is common for all enteropathogenic microorganisms and does not rule out the possibility that such strains can cause diarrhoea when they colonise "susceptible" intestines where the bacterial flora or the mucosal defences are immature, as in infants and young children.

Another important issue is whether ETBF strains belong to a single clone or cluster. All attempts to find phenotypic or genotypic similarities have failed; serology, ${ }^{21}$ restriction fragment length polymorphism of $\mathrm{rRNA}^{22}$ and restriction endonuclease analysis of DNA $^{16}$ have demonstrated that ETBF strains comprise a heterogeneous population. In the present study, plasmid profiles of ETBF strains were examined to determine whether the heterogeneity of ETBF was reflected in the plasmid fingerprinting and whether toxin production was associated with the presence of a particular plasmid. Only half of the ETBF strains had extra-chromosomal bands and the plasmid profiles of those with such bands were different, confirming the heterogeneity of the strains examined. Plasmid fingerprinting could be a useful marker for epidemiological studies; two isolates from the same healthy carrier were distinguished by their different plasmid profiles.

In conclusion, ETBF strains were isolated at an appreciable and similar frequency from faeces and from extra-intestinal samples. The data indicate that the role played by these $B$. fragilis strains could be important and deserves further investigation.

We are grateful to Fabiana Superti for help with cell culture and to Rita Cardines and Antonella Frate for performing plasmid preparations.

9. Myers LL, Shoop DS, Stackhouse LL et al. Isolation of enterotoxigenic Bacteroides fragilis from humans with diarrhea. J Clin Microbiol 1987; 25 : 2330-2333.

10. Weikel CS, Grieco FD, Reuben J, Myers LL, Sacks RB. Human colonic epithelial cells, HT2 $9 / \mathrm{Cl}$, treated with crude Bacteroides fragilis enterotoxin dramatically alter their morphology. Infect Immun 1992; 60: 321-327.

11. Van Tassell RL, Lyerly DM, Wilkins TD Purification and characterization of an enterotoxin from Bacteroides fragilis. Infect Immun 1992; 60: 1343-1350.

12. Holdemann LV, Cato EP, Moore WEC (eds). Anaerobe laboratory manual. Blacksburg, Virginia Polytechnic Institute and State University. 1977.

13. Maniatis $\mathbf{T}$, Fritsch EF, Sambrook $\mathbf{J}$ (eds). Molecular cloning. A laboratory manual. Cold Spring Harbor, NY, Cold Spring Harbor Laboratory. 1982: 368-369.

14. Pantosti A, Tzianabos AO, Onderdonk AB, Kasper DL. Immunochemical characterization of two surface polysaccharides of Bacteroides fragilis. Infect Immun 1991; 59: 2075-2082.

15. Shoop DS, Myers LL, LeFever JB. Enumeration of enterotoxigenic Bacteroides fragilis in municipal sewage. Appl Environ Microbiol 1990; 56: 2243-2244. 
16. Sack RB, Myers LL, Almeido-Hill J et al. Enterotoxigenic Bacteroides fragilis: epidemiologic studies of its role as a human diarrhoeal pathogen. Diarrhoeal Dis Res 1992; 10: 4-9.

17. San Joaquin V, Weikel C. Enterotoxigenic Bacteroides fragilis a cause of childhood diarrhoea? Abstracts of the 1992 ICAAC. Washington, DC, American Society for Microbiology. 1992: no. 192

18. Ingham HR, Eaton S, Venables CW, Adams PC. Bacteroides fragilis resistant to metronidazole after long-term therapy. Lancet 1978; 1: 214.

19. Pantosti A, Tzianabos AO, Reinap BG, Onderdonk AB, Kasper
DL. Bacteroides fragilis strains express multiple capsular polysaccharides. J Clin Microbiol 1993; 31 : 1850-1855.

20. Tzianabos AO, Onderdonk AB, Rosner B, Cisneros RL, Kasper DL. Structural features of polysaccharides that induce intra-abdominal abscesses. Science $1993 ; 262$ : 416-419.

21. Myers LL, Shoop DS. Antigenic characteristics of enterotoxigenic and nonenterotoxigenic isolates of Bacteroides fragilis. Am J Vet Res 1987; 48: 643-645.

22. Smith CJ, Callihan CJ. Analysis of rRNA restriction fragment length polymorphisms from Bacteroides spp. and Bacteroides fragilis isolates associated with diarrhoea in humans and animals. J Clin Microbiol 1992; 30: 806-812. 